DOI: $10.51423 / 2524-0471-2020-11-2-5$

\title{
COMMUNICATIVE-COMPENSATORY PROCESSES ON SOCIAL NETWORK
}

\author{
Tetyana KHRABAN, \\ orcid.org/0000-0001-5169-5170 \\ Candidate of Philological Science, \\ Head of the Department of Foreign Languages \\ of the Military Institute of Telecommunications and Information Technologies (Ukraine, Kyiv) \\ Xraban.Tatyana@gmail.com
}

\section{Igor KHRABAN,}

orcid.org/0000-0003-3319-8538

Doctor of Political Science, Professor

Professor of Interregional Academy of Personnel Management (Ukraine, Kyiv)

khraban728@gmail.com

\section{ANNOTATION}

The aim of the article is to identify the specifics of communicative-compensatory processes on social network. Materials \& methods. In order to achieve that objective, the general scientific research methods: analysis, classification, observation, description were used. In addition, as part of an integrated sociolinguistic approach, discourse analysis and a quantitative research method were used. Publications posted in the Ukrainian sector of an American online social media and social networking service Facebook served as an input for the research. Results \& discussions. The study identified three modes of communicative-compensatory processes, which are arranged in descending order according to their proportions: 1) communicative-compensatory process characterized by a correlation with the defense mechanism "overcompensation". During this process personal growth and radical transformations of the whole personality occur on the basis of the dialogical mutual affirmation of "I" and "You". At the linguistic level, such mode is manifested owing to the use of a preferable image (real or illusory) to affirm one's strength, significance, value, that is, for self-assertion and rising in status; 2) process characterized by a correlation with the defense mechanism "direct compensation" and which shows itself as adaptive in nature and does not contribute to the personal growth. At the linguistic level such mode is manifested in the individual concentrating on his own interests, feelings and needs and orientation on consumption; 3) process characterized by a correlation with the defense mechanism "illusive overcompensation" and which nature is emotional vampirism. At the linguistic level such mode is manifested in the watching out for another person's imaginary or real flaws with the purpose of emphasizing and exaggerating. Conclusion. A specific feature of communicative-compensatory processes in social networks is that they mainly act as representations of the compensatory function of autocommunication. The dominant form of compensatory autocommunication in social networks is an internal monologue. The verbal implementation of communicative-compensatory processes in social networks are: 1) posts in which the protest gains the power of critical confrontation and is a synonym for the right to individual free development; 2) posts aimed at humiliation and criticism; 3) posts containing advice, support, comfort to the troubled "I". 
Key words: autocommunication, communicative-compensatory processes, social networks, sociology of the internet.

\title{
КОММУНИКАТИВНО-КОМПЕНСАТОРНЫЕ ПРОЦЕССЫ В СОЦИАЛЬНЫХ СЕТЯХ
}

\author{
Татьяна ХРАБАН, \\ orcid.org/0000-0001-5169-5170 \\ кандидат филологических наук, \\ дочент кафедры иностранных языков \\ Военного института телекоммуникациии и информатизации \\ Игорь ХРАБАН \\ orcid.org/0000-0003-3319-8538 \\ доктор политических наук, профессор, \\ профессор Межрегиональной академии управления персоналом
}

\section{Вступ}

Научно-техническая революция, а также связанные с ними процессы развития системы массовой коммуникации и компьютеризация стали факторами, детерминирующими коренные изменения в условиях и средствах общения людей (Brignall \& Van Valey, 2005), поэтому не случайно сегодня интернет рассматривается как платформа проведения социологических исследований, направленных на верификацию теории распространения технологий и медиаэффектов в социальных сетях, способных уникально объединять способы коммуникации и формы контента (DiMaggio et al., 2001). Социальные сети имеют ключевое значение для организации интернет-коммуникации благодаря той роли, которую они играют в организации социального взаимодействия, поддержки, информирования, формирования чувства групповой принадлежности и социальной идентичности. Сегодня мы можем говорить о социальных сетях как о своеобразном паллиативе, к которому прибегают субъекты для решения такой проблемы, как «нереализованность личности в сфере её повседневного общения, ощущаемой как дефицит эмоционально насыщенных личностно ориентированных связей, отсутствие сочувствия и сопереживания, трудности для осуществления самоутверждения и т.д.» (Гладышев, 2001: 4), и которую интернетпользователи пытаются решить путём компенсаторного общения, осуществляемого в определённых группах (сообществах) социальных сетей. Потенциал социальных сетей как среды компенсаторного общения реализуется путем сочетания системы ценностей, норм, традиций и коммуникативных запросов личности с коммуникативными возможностями группы, преобразующими исходный коммуникативный мир участника группы (Diomidous et al,, 2016; Adam-Troian, 2020). В период развития информационно-коммуникационных технологий проблема компенсаторного общения обретает особую актуальность, поскольку имеет непосредственное отношение к социальным и социально-психологическим результатам происходящих трансформаций в коммуникации.

Анализ последних исследований и публикаций. Сегодня разнообразие подходов к пониманию коммуникации стало очевидным, что свидетельствует о сложности феномена коммуникации. Кроме того, данная работа служит подтверждением того, что в науке есть устойчивая тенденция к интеграции теорий и концепций разных научных знаний. Междисциплинарные исследования, к которым относится и данная работа, не образуют 
бесструктурное смешение разноплановых и разноуровневых знаний, а взаимно дополняют друг друга, обогащая теорию и практику социальных коммуникаций. Для подготовки этой статьи значимыми являются научные работы в области социолингвистики, психолингвистики, социологии и психологии, акцент в которых сделан на способах позиционирования личности в интернет-коммуникации, а также работы, изучающие проблематику компенсаторного общения с позиции гармонизации коммуникативного мира личности (группы), а именно: В. Гладышева (Гладышев, 2001) (изучено особенности коммуникативно-компенсаторных процессов); Е. Кондрашевой, М. Тонких (Кондрашева \& Тонких, 2019) (охарактеризовано способы самопрезентации в интернет-ресурсах, которые использует современное поколение для самовыражения и самореализации); J. Adam-Troian, E. Bonetto, F. Varet, T. Arciszewski, G. Dezecache (Adam-Troian et al., 2020) (рассмотрено адаптивную ценность социальных сетей); W. Zhang, B. Guo (Zhang \& Guo, 2017) (выделено и исследовано три основных типа механизмов психологической защиты: изоляция, компенсация и саморассеяние); L. Leonard (Leonard, 2000) (квалифицированы различные виды компенсации, влияющие на личность, успех и душевное равновесие личности) и другие. В данном исследовании впервые, основываясь на эмпирическом материале, было рассмотрено компенсаторное общение как социально-психологический аспект поведения индивида в интернет-пространстве. Научная ценность исследования состоит в дальнейшем развитии теории социологии интернета, предметом изучения которой является аудитория интернета и формы социально-культурного взаимодействия между людьми в интернетпространстве как особой социальной, психологической и культурной среды. Цель статьи выявить специфику коммуникативно-компенсаторных процессов в социальных сетях.

\section{Методы исследования}

Для достижения поставленной цели в работе использовались общенаучные методы исследования: анализ, классификация, наблюдение, описание. Кроме того, с целью анализа социальных феноменов и процессов, структуры и особенностей социальных интеракций внутри группы считаем оправданным задействование методологического подхода, основывающегося на рассмотрении дискурса как социальной практики (Contemporary Critical Discourse Studies, 2014: 3), в которой определяющим фактором «выступает социальная, коммуникативная природа человека, реализующаяся через её взаимодействие с социумом в семиотической, в частности, языковой среде жизнедеятельности» (Савелюк, 2017: 10). Конструирование новой социальной реальности на основе интернет-коммуникации внесло существенные коррективы в интерпретацию традиционно исследуемых социальных процессов и феноменов, а также возможной идентификации ранее неизвестных. Поэтому актуальными являются методологические подходы, углубляющие представления об уже изученных социальных процессах и феноменах (Кочубейник, 2017: 88). Одним из популярных методов современной социологии является дискурс-анализ (Бочелюк \& Панов, 2018: 84), отправной точкой которого является утверждение, что «мы получаем доступ к реальности с помощью языка. С помощью языка мы создаём репрезентации реальности, которые не просто отражают то, что в ней есть, но и конструируют её» (Jorgensen \& Phillips, 2002). Иными словами, «язык - это не просто канал передачи информации о явлениях, фактах или о поведении людей, а «механизм», который генерирует и конституирует социальный мир» (Jorgensen \& Phillips, 2002). Дискурсивная парадигма исследования социальных сетей соответствует новейшей тенденции обращения исследователя к реальному человеку и жизненным ситуациям. Поскольку дискурс - междисциплинарный объект, то расширяется сфера контактов как со смежными дисциплинами, в частности с различными отраслями психологии. Тем самым «создаются условия для обширного и разнообразного 
применения получаемых данных и, что не менее важно, открываются новые темы, которые ранее были скрыты так называемыми «границами» между различными отраслями знания» (Ситуационная и личностная детерминация дискурса, 207: 28-29). В контексте данного исследования дискурс-анализ помогает синхронно исследовать организацию и процесс компенсаторного общения - описать и объяснить динамику взаимодействия и коммуникации в социальных сетях, а также статические свойства процесса. Материалом проведённого нами эмпирического исследования послужили письменные публикации (посты), размещённые в украинском секторе социальной сети Facebook.

\section{Результаты и дискуссии}

Данное исследование опирается на разработанную В. Гладышевым концепцию компенсаторного общения, поскольку она может служить одной из теоретических моделей понимания основ интернет-коммуникации. Компенсаторное общение рассматривается как такое, что направлено на гармонизацию коммуникативного мира личности в случае нехватки тесных эмоциональных связей с людьми, дефицита близких, интимных, доверительных отношений, что обычно переживается как одиночество (Гладышев, 2001: 29). Важным элементом в определении компенсаторного общения является его прагматический аспект, а именно - жажда эмоционального насыщения и стремление к самоутверждению (Leonard, 2000). Компенсаторное общение является манифестацией на языковом уровне действия механизма психологической защиты «компенсация», который направлен на сохранение определенного равновесия внутреннего мира личности, возобновление устойчивости, целостности, способность оставаться тождественным себе, что часто нарушается внешними воздействиями и внутренними изменениями (Domino, 1976). Объединяя психологические и лингвистические аспекты в одном понятии, мы можем говорить о коммуникативнокомпенсаторных процессах, происходящих в социальных сетях. Протекание этих процессов может осуществляться по-разному. Так, для первого модуса, удельный вес которого является незначительным в социальных сетях (13\% от массива выборки), характерным является обращение к такой форме механизма психической защиты, как «прямая компенсация». В социальной сфере этот механизм носит адаптивный характер, не выводя личность за пределы привычного коммуникативного мира, не способствуя её личностному росту (Гладышев, 2001: 17). В социальных сетях на языковом уровне первый модус коммуникативнокомпенсаторных процессов проявляется в сосредоточении индивида на своих интересах, чувствах и потребностях, ориентации на потребление: Совет женщинам: если мужчина постоянно ищет в тебе недостатки, не нужно что-то менять в себе. Стоит поменять мужчину, и ты снова - красавища, умница и вкусно готовишь (FB). Такой коммуникативнокомпенсаторный процесс характеризуется неким «эгоцентризмом» (Гладышев, 2001: 26), который преодолевается при обращении субъекта к механизму психической защиты «сверхкомпенсация». Действие этого механизма сопряжено «с усилиями по гармонизации внутреннего мира ближнего и достижима лишь при условии решения этой задачи» (Гладышев, 2001: 26). Наряду с этим происходит личностный рост и радикальные преобразования личности в целом на основе диалогического взаимоутверждения (Гладышев, 2001: 27). На языковом уровне такой модус коммуникативно-компенсаторных процессов манифестируется в 38\% выборки и проявляется в признании другой личности неповторимой индивидуальностью, преклонении перед его достоинствами. Тем самым субъекты используют этот образ (реальный или иллюзорный) для утверждения своей силы, значимости, ценности, то есть для самоутверждения и повышения статуса: Люди, которые говорят правду и показывают свои чувства, вовсе не слабы, глупьл или наивнь. Они настолько сильны, что не нуждаются в маске (FB). Характерной особенностью второго 
модуса коммуникативно-компенсаторных процессов в социальных сетях является то, что достижение пользователями интернета поставленной им коммуникативной цели часто происходит через интеграцию вербальных компонентов с визуальными образами известных людей (мифических героев, персонажей книг, фильмов, национальных героев и др.) благодаря эксплуатации разветвлённых осознаваемых и неосознаваемых ассоциативных связей, например, коррелятами образа сэра Уинстона Черчилля в социальных сетях являются: У тебя есть враги? Хорошо. Значит, в своей жизни ты что-то когда-то отстаивал (FB). Приведённые примеры доказывают, что для второго модуса коммуникативно-компенсаторных процессов характерно создание целостного образа на основе диалогического взаимоутверждения «Я - Ты» или «Я - Мы» с опорой, безусловно, на выдающиеся черты другой личности (субъективированного объекта).

Отличительной чертой третьего модуса коммуникативно-компенсаторных процессов является то, что гармонизация внутреннего мира субъекта как его коммуникативная интенция осуществляется посредством иллюзорной сверхкомпенсации (декомпенсации). При этом желаемое психологическое равновесие достигается субъектом путем отрицания других, то есть за счёт дегармонизации коммуникативного мира другой личности или углубления уже имеющейся у неё дисгармонии. На языковом уровне такой модус коммуникативно-компенсаторных процессов манифестируется в 49\% выборки и проявляется в выискивании у другой личности (субъективированного объекта) наиболее уязвимых сторон, мнимых или реальных недостатков, которые акцентируются и иногда гипертрофированно преувеличиваются до карикатурного искажения: Если Вам за сорок, не беда, что Bы перестали видеть маленькие буквы, зато Вы стали видеть издалека идиотов (FB).

Специфической особенностью коммуникативно-компенсаторных процессов в социальных сетях является то, что они преимущественно выступают как репрезентации компенсаторной функции аутокоммуникации. На практике это проявляется в выставлении пользователями интернета на страничках какой-либо группы постов, содержащих в себе элементы компенсаторного общения. Причём заведомо содержание в них такого плана, которое не предполагает комментариев со стороны других участников группы, что и подтверждается их низкой активностью (количеством комментариев и лайков) в отношении этих публикаций. В. Мацута характеризует аутокоммуникацию как «динамический процесс, в котором человек «встречается с самим собой» через взаимодействие с миром» (Мацута, 2010), то есть в определении акцентируется взаимодействие, диалог ипостасей личности, образов «Я»: Доведись мне поговорить с самой собой - той, что была молода, что бы я сказала? Живи. Живи, как будто у тебя будет тысяча жизней. Но помни, что у людей, которые рядом, жизнь одна. Не испорти её (FB). Аутокоммуникация может выступать как простое взаимодействие различных «смысловых позиций»: Это очень странное чувство, когда тебе так не хватает общения. Но в то же время ты понимаешь, что не хочешь общаться ни $с$ кем (FB). В. Измагурова рассматривает аутокоммуникацию как представляемую коммуникацию, то есть при таком подходе акцентируется способность субъекта представлять партнёра и общаться с ним в условиях его реального отсутствия (Измагурова, 2015: 127-128): Иногда хочется крикнуть: «Остановите жизнь, я устала!». Но ангел-хранитель легонько дотронется до твоего плеча и шепнет: «Не твоя остановка, живи...» (FВ). По мнению исследовательницы, «представленность одного человека в сознании другого человека, также обладающего сознанием, является необходимым условием, позволяющим считать аутокоммуникацию видом или уровнем социальной коммуникации» (Измагурова, 2015: 127-128). В этой статье подход к пониманию понятия «аутокоммуникация» основывается на работе B. Alderson-Day и C. Fernyhough, в которой 
скрытый разговор с самим собой и общение с воображаемым партнёром рассматриваются как частные ситуации в границах аутокоммуникации. Общим для этих форм аутокоммуникации является выполнение единой функции - обеспечения психологической целостности личности на основе самоопределения и самоидентификации (Alderson-Day \& Fernyhough, 2015). Дискурс-анализ доказал, что доминирующей формой компенсаторной аутокоммуникации в социальных сетях является внутренний монолог (61\% от общей выборки). Аутокоммуникация как внутренний монолог понимается как форма, способ сложного, однонаправленного воздействия человека на себя. Само высказывание оказывает на человека определённое воздействие. Также монолог является формой разных умственных действий, например, он может быть способом выражения конечного результата своих рассуждений. В данном контексте в общении с собой выражается только одна смысловая позиция (Кабрин et al.: 106): Хорошо, что есть время, расстояние и трудности. Именно они дают понять, кто любит, кто дружит, а кто вовсе не нужен (FВ). Субъект сам произносит монолог и сам анализирует его. В контексте коммуникативно-компенсаторных процессов монолог становится инструментом для самоутешения ( $А$ я уйду, тебя не замечая, конфетку шоколадную жуя. И пусть тебя полюбит лошадь злая, а не такое солнышко, как я) (FВ), самовнушения (Человек никогда не должен стылдтся признаваться в своих ошибках. Ибо, признаваясь в них, он признаётся в том, что сегодня он мудрее, чем был вчера) (FB), самооценки (Я давно усвоила урок: если тебя не любит мужчина твоей жизни, лучшая месть - хорошо выглядеть) (FB) и оценки других (Мужчину должны украшать три вещи: порядочность, характер и поступки, а не дешёвые понты, завышенная самооценка $и$ длинный язык) (FB).

В 39\% общей выборки формой компенсаторной аутокоммуникации в социальных сетях был выявлен внутренний диалог. Представляя собой интрапсихический процесс, внутренний диалог направлен как на разрешение интеллектуально-неоднозначной, конфликтной проблематики, так и на преобразование личностно и эмоционально значимых содержаний сознания (Измагурова, 2015: 37-38). Как форма аутокоммуникации, внутренний диалог показывает наличие в сознании человека разных смысловых позиций ( $B$ моменты, когда тебе нужна поддержка, ты обычно оказываешься никому не нужен. Это неправда! На самом деле ты постоянно никому не нужен. Просто замечаешь это тогда, когда тебе нужна поддержка... А в итоге ты осознаешь, что единственные руки, в которые ты сможешь упасть и расплакаться, - это твои собственные) (FВ) или интериоризированные образы важных для субъекта людей (Требовать чистоту в доме может только тот мужчина, который дал этот дом женщине. Ждать вкусного ужина может только тот мужчина, который купил продукты для его приготовления) (FВ). В. Кабрин отмечает, что «во внутреннем диалоге «Я» человека может идентифицироваться с позицией любого из внутренних собеседников, выражая его мысли и чувства, в отличие от внешнего общения, когда высказывание осуществляется человеком от своего лица» (Кабрин et al.: 2011: 108).

Манифестацией внутреннего диалога в рамках компенсаторной аутокоммуникации в социальных сетях являются посты, направленные на личностные изменения путем осмысления результатов самонаблюдения и преобразования собственных привычных способов самовосприятия и восприятия окружающего мира. Поскольку структура вербализованной формы внутреннего диалога не соответствует структуре внешнего диалога, маркерами диалогической формы аутокоммуникации являются наличие двух и более несовпадающих точек зрения относительно одной темы (Время лечит! Серьёзно!? А кого оно вылечило? Его? Её? Время никого не вылечило! Однозначно! Вылечил новый человек, так вовремя появившийся в жизни, вылечили новые увлечения, хобби, погружённость в работу... но только не время!) (FВ), присутствие в тексте образов других (Раньше я думала, 
что нужно беречь дружбу, хорошие отношения. А сейчас поняла - нужно беречь себя - от лицемерных людей, которые, ульбаясь в глаза, тихо ненавидят за спиной) (FB), речевых оборотов, указывающих на обращение субъекта к собеседнику, например, императивов (Не могу понять, зачем люди, однажды уже покинув меня, снова лезут в мою жизнь? Ушли? Ну и валите! Я мусор не коллекциионрую!!!) (FВ), присутствие в тексте Я-, Ты-высказываний (Моя доброта заканчивается там, где Ваша наглость переходит границы) (FВ), глаголов во втором лице (У умных женщин всегда есть своя личная жизнь. А глупье всегда лезут в чужую) (FB).

Подытоживая проведённое исследование, следует определить установившиеся формы вербальных (вербально-визуальных) сообщений, которые отражают коммуникативнокомпенсаторные процессы в социальных сетях: 1) посты, в которых протест приобретает силу критического противостояния и служит синонимом права на свободное развитие личности. Убежденный в своей правоте, субъект принципиально защищает целостность своей личности, принципиально возражает против посягновений на свои границы. При этом важную роль в таких постах играют ценностные суждения, в которых даются оценки «хорошо» / «плохо»: Часто мужчинь возмущаются, увидев, что из тонкой и звонкой девочки, которой когда-то была их возлюбленная, вдруг вылупилась тётка... Классическая тётка со сниженным кругозором, ограниченной покупкой тушёнки «по акции» и наймом репетиторов для ребенка. С короткой стрижкой, в трусах в горошек, с пирожным 8 перерыве на работе, в странной одежде немарких иветов, больше напоминающей парашют. Откуда они вообще берутся - эти тётки? Тётками становятся женщины, которые живут не для себя. Женщины, которые вынуждены ежедневно и ежечасно поступать вопреки своим желаниям. Что заставляет их делать это? Вероятно, долг (FВ); 2) посты, направленные на унижение и критику. Субъект не находит в себе ресурсов для самоактуализации и выбирает способ компенсации за счёт других людей. Реализуется поиском недостатков других людей, а также интерпретацией их поступков в негативном плане. Прослеживается чувство неполноценности собственного «Я», которое необходимо компенсировать для полноценного взаимодействия в социуме. Важную роль в таких постах играют ценностные суждения, в которых даётся оценка «плохо»: Не понимаю, зачем мерять температуру на входе в супермаркет? Где Вы видели, чтобы мужик с температурой 37 куда-то ходил? (FВ); 3) посты, содержащие совет, поддержку, утешение находящемуся в затруднительном положении «Я». Зачастую предполагается, что совет даётся авторитетной личностью или сильным, конкурентоспособным в обществе субъектом: Самое важное - это навести порядок в душе. Соблюдаем три «не»: не жалуемся, не обвиняем, не оправдываемся (FB).

\section{Выводы}

Протекание коммуникативно-компенсаторных процессов в социальных сетях осуществляется разными путями. В исследовании было выделено три модуса коммуникативно-компенсаторных процессов, которые расположены в порядке убывания их удельного веса: 1) коммуникативно-компенсаторный процесс, характеризующийся корреляцией с механизмом психической защиты «сверхкомпенсация». При этом происходит личностный рост и радикальные преобразования личности в целом на основе диалогического взаимоутверждения «Я» и «Ты». На языковом уровне такой модус проявляется в использовании кристаллизованного образа (реального или иллюзорного) для утверждения своей силы, значимости, ценности, то есть для самоутверждения и повышения статуса; 2) процесс, характеризующийся корреляцией с механизмом психической защиты «прямая компенсация», носящий адаптивный характер и не способствующий личностному росту 
субъекта. На языковом уровне такой модус проявляется в сосредоточении индивида на своих интересах, чувствах и потребностях, ориентацией на потребление; 3) процесс, характеризующийся корреляцией с механизмом психической защиты «иллюзорная сверхкомпенсация», носящий характер психологического вампиризма. На языковом уровне такой модус проявляется в выискивании у другой личности мнимых или реальных недостатков, которые акцентируются и гипертрофированно преувеличиваются.

Специфической особенностью коммуникативно-компенсаторных процессов в социальных сетях является то, что они преимущественно выступают как репрезентации компенсаторной функции аутокоммуникации. Доминирующей формой компенсаторной аутокоммуникации в социальных сетях является внутренний монолог. Вербальной реализацией коммуникативно-компенсаторных процессов в социальных сетях являются: 1) посты, в которых протест приобретает силу критического противостояния и служит синонимом права на свободное развитие личности; 2) посты, направленные на унижение и критику; 3) посты, содержащие совет, поддержку, утешение находящемуся в затруднительном положении «Я».

\section{Литература}

Бочелюк, В., Панов, М. (2018). Проблемне поле психолінгвістичних досліджень дискурсу соціальних онлайн-мереж. Psycholinguistics, 24(1), 79-96.

Гладышев, В. И. (2001). Компенсаторное общзение: социально-философский анализ: автореф. дисс. ... доктора филос. наук. Екатеринбург.

Измагурова, В. Л. (2015). Феномен аутокоммуникации как фактор развития сознания. Коммуникология, 4, 31-44.

Кабрин, В. И., Рыльская, Е. А., Петрова, В. Н., Мацута, В. В., Частоколенко, Я. Б., Мещерякова, Э. И., Пяткова, О. А., Лебединская, С. В. (2011). Транскоммуникаиия: преобразование жизненных миров человека. Томск: Изд-во Том. ун-та.

Кондрашева, Е. В., Тонких, М. С. (2019). Текст и личность в виртуальной реальности. Эпоха науки, 18, 130-133. DOI: 11.24411/2409-3203-2018-11829.

Кочубейник, О.М. (2017). Соціально-психологічні дослідження: методологічні симптоми неблагополуччя. Збірник наукових статей Київського міжнародного університету й Інституту соціальної та політичної психологї̈ НАПН України, 10, 83-98.

Мацута, В. В. (2010). Аутокоммуникация человека: функциональный аспект: автореф. дис. ... канд. психол. наук. Том. гос. ун-т.

Савелюк, Н. (2017). Психологія розуміння релігійного дискурсу. Київ: КНТ.

Ситуационная и личностная детерминация дискурса (2007). Под ред. Н.Д. Павловой, И.А. Зачесовой. Москва: Изд-во «Институт психологи РАН».

Adam-Troian, J., Bonetto, E., Varet, F., Arciszewski, T., \& Dezecache, G. (2020). Explaining social behavior in response to death-related threats: The conspecific loss compensation mechanism. Evolutionary Behavioral Sciences. Advance online publication. URL: https://psycnet.apa.org/record/2020-26624-001. DOI: 10.1037/ebs0000202.

Alderson-Day, B. \& Fernyhough, C. (2015). Inner Speech: Development, Cognitive Functions, Phenomenology, and Neurobiology. Psychological bulletin, 141(5), 931-965. DOI: 10.1037/bul0000021.

Brignall T., Van Valey T. (2005).The impact of Internet communications on social interaction. Sociological Spectrum, 25(3), 335-348. DOI: 10.1080/02732170590925882.

Contemporary Critical Discourse Studies (2014). Ed. by C. Hart and P. Cap. London: Bloomsbury Academic. 
DiMaggio P., Hargittai E., Neuman W.R., Robinson J.P. (2001). Social Implications of the Internet Author(s). Annual Review of Sociology, 27, 307-336. DOI: 10.1146/annurev.soc.27.1.307.

Diomidous, M., Chardalias, K., Magita, A., Koutonias, P., Panagiotopoulou, P., \& Mantas, J. (2016). Social and Psychological Effects of the Internet Use. Acta informatica medica: AIM: journal of the Society for Medical Informatics of Bosnia \& Herzegovina: casopis Drustva za medicinsku informatiku BiH, 24(1), 66-68. DOI: 10.5455/aim.2016.24.66-68.

Domino, G. (1976). Compensatory aspects of dreams: An empirical test of Jung's theory. Journal of Personality and Social Psychology, 34(4), 658-662. DOI: 10.1037/0022-3514.34.4.658.

Jorgensen, M., \& Phillips, L. (2002). Discourse analysis as theory and method. London: Sage Publications.

Leonard L.M. (2000). I-D Compensation Theory: Some Implications of Trying to Satisfy Immediate-Return Needs in a Delayed-Return Culture. Psychological Inquiry Copyright, 10(3), 195-208.

Zhang, W., Guo, B. (2017). Resolving defence mechanisms: A perspective based on dissipative structure theory. Int J Psychoanal, 98 (2), 457-472. DOI: 10.1111/1745-8315.12623.

\section{Источники}

FB (Facebook). Retrieved from https://www.facebook.com/groups/ 655994877875713/.

\section{References}

Bochelyuk, V., Panov, M. (2018). Problemne pole psikholingvistichnikh doslidzhen diskursu soczialnikh onlajn-merezh [The problem field of psycholinguistic research of the social online networks discourse]. Psycholinguistics, 24(1), 79-96 [In Ukrainian].

Gladyshev, V. I. (2001). Kompensatornoe obshhenie: soczialno-filosofskij analiz [Compensatory Communication: A Socio-Philosophical Analysis]. (Doctor Dissertation). Ekaterinburg [In Russian].

Izmagurova, V. L. (2015). Fenomen autokommunikaczii kak faktor razvitiya soznaniya [The phenomenon of autocommunication as a factor in the development of consciousness]. Kommunikologiya, 4, 31-44 [In Russian].

Kabrin, V. I., Rylskaya, E. A., Petrova, V. N., Maczuta, V. V., Chastokolenko, Ya. B., Meshheryakova, E. I., Pyatkova, O. A., Lebedinskaya, S. V. (2011). Transkommunikacziya: preobrazovanie zhiznennykh mirov cheloveka [Transcommunication: the transformation of human life worlds]. Tomsk: Izd-vo Tom. un-ta [In Russian].

Kondrasheva, E. V., Tonkikh, M. S. (2019). Tekst i lichnost v virtualnoj realnosti [Text and personality in virtual reality]. Epokha nauki, 18, 130-133. DOI: 11.24411/2409-3203-201811829 [In Russian].

Kochubejnik, O.M. (2017). Soczialno-psikhologichni doslidzhennya: metodologichni simptomi neblagopoluchchya [Socio-psychological research: methodological symptoms of trouble]. Zbirnik naukovikh statej Kiyivskogo mizhnarodnogo universitetu $j$ Institutu soczialnoyi ta politichnoyi psikhologiyi NAPN Ukrayini, 10, 83-98 [In Ukrainian].

Macuta, V. V. (2010). Autokommunikaciya cheloveka: funkcionalnyj aspect [Human autocommunication: functional aspect]. (Candidate Dissertation). Tom. gos. un-t [In Russian].

Savelyuk, N. (2017). Psikhologiya rozuminnya religijnogo diskursu [Psychology of understanding religious discourse]. Kyiv: KNT [In Ukrainian].

Situaczionnaya $i$ lichnostnaya determinacziya diskursa (2007). [Situational and Personal Determination of Discourse]. Pod red. N.D. Pavlovoj, I.A. Zachesovoj Moscow: Izd-vo «Institut psikhologi Russian Academy of Sciences» [In Russian].

Adam-Troian, J., Bonetto, E., Varet, F., Arciszewski, T., \& Dezecache, G. (2020). Explaining social behavior in response to death-related threats: The conspecific loss compensation mechanism. 
Evolutionary Behavioral Sciences. Advance online publication. URL: https://psycnet.apa.org/record/2020-26624-001. DOI: 10.1037/ebs0000202 [in English].

Alderson-Day, B. \& Fernyhough, C. (2015). Inner Speech: Development, Cognitive Functions, Phenomenology, and Neurobiology. Psychological bulletin, 141(5), 931-965. DOI: 10.1037/bul0000021 [in English].

Brignall T., Van Valey T. (2005).The impact of Internet communications on social interaction. Sociological Spectrum, 25(3), 335-348. DOI: 10.1080/02732170590925882 [in English].

Contemporary Critical Discourse Studies / Ed. by C. Hart and P. Cap. (2014). London: Bloomsbury Academic [in English].

DiMaggio P., Hargittai E., Neuman W.R., Robinson J.P. (2001). Social Implications of the Internet Author(s). Annual Review of Sociology, 27, 307-336. DOI: 10.1146/annurev.soc.27.1.307 [in English].

Diomidous, M., Chardalias, K., Magita, A., Koutonias, P., Panagiotopoulou, P., \& Mantas, J. (2016). Social and Psychological Effects of the Internet Use. Acta informatica medica: AIM: journal of the Society for Medical Informatics of Bosnia \& Herzegovina: casopis Drustva za medicinsku informatiku BiH, 24(1), 66-68. DOI: 10.5455/aim.2016.24.66-68 [in English].

Domino, G. (1976). Compensatory aspects of dreams: An empirical test of Jung's theory. Journal of Personality and Social Psychology, 34(4), 658-662. DOI: 10.1037/0022-3514.34.4.658 [in English].

Jorgensen, M., \& Phillips, L. (2002). Discourse analysis as theory and method. London: Sage Publications [in English].

Leonard L.M. (2000). I-D Compensation Theory: Some Implications of Trying to Satisfy Immediate-Return Needs in a Delayed-Return Culture. Psychological Inquiry Copyright, 10(3), 195-208 [in English].

Zhang, W., Guo, B. (2017). Resolving defence mechanisms: A perspective based on dissipative structure theory. Int J Psychoanal, 98 (2), 457-472. DOI: $\underline{10.1111 / 1745-8315.12623}$ [in English].

\title{
Sources
}

FB (Facebook). Retrieved from https://www.facebook.com/groups/ 655994877875713/.

\section{КОММУНИКАТИВНО-КОМПЕНСАТОРНЫЕ ПРОЦЕССЫ В СОЦИАЛЬНЫХ СЕТЯХ}

\author{
Татьяна ХРАБАН, \\ кандидат филологических наук, \\ дочент кафедры иностранных языков \\ Военного института телекоммуникаций и информатизации \\ Игорь ХРАБАН, \\ доктор политических наук, профессор, \\ профессор Межрегиональной академии управления персоналом
}

Цель статьи - выявить специфику коммуникативно-компенсаторных процессов в сочииальных сетях.

Материалы и методы. Для достижения поставленной цели в работе использовались общенаучные методы исследования: анализ, классификация, наблюдение, описание. Кроме того, в рамках комплексного сочиолингвистического подхода были использованы дискурс- 
анализ и квантитативный метод исследования. Материалом исследования послужсии письменные публикации (посты), размещённые в украинском секторе социальной сети Facebook.

Результаты и дискуссии. В исследовании было выделено три модуса коммуникативно-компенсаторных проиессов, которые расположены в порядке убывания их удельного веса: 1) коммуникативно-компенсаторный процесс, характеризующийся коррелячией с механизмом психологической защить «сверхкомпенсачия». При этом происходит личностный рост и радикальные преобразования личности в целом на основе диалогического взаимоутверждения «Я» $и$ «Ты»». На языковом уровне такой модус проявляется в использовании кристаллизованного образа (реального или иллюзорного) для утверждения своей силь, значимости, ценности, то есть для самоутверждения $u$ повышения статуса; 2) проиесс, характеризующийся корреляцией $с$ механизмом психологической защиты «прямая компенсация», носящий адаптивный характер и не способствующий личностному росту субъекта. На языковом уровне такой модус проявляется в сосредоточении индивида на своих интересах, чувствах и потребностях, ориентаџией на потребление; 3) процесс, характеризуюшийся корреляцией с механизмом психологической зашиты «иллюзорная сверхкомпенсация», носящий характер психологического вампиризма. На языковом уровне такой модус проявляется в выискивании y другой личности мнимых или реальных недостатков, которые акцентируются $u$ гипертрофированно преувеличиваются.

Выводы. Специфической особенностью коммуникативно-компенсаторных процессов в сочиальных сетях является то, что они преимущественно выступают как репрезентации компенсаторной функции аутокоммуникации. Доминирующей формой компенсаторной аутокоммуникации в сочиальных сетях является внутренний монолог. Вербальной реализацией коммуникативно-компенсаторных процессов в социальных сетях являются: 1) nосты, в которых протест приобретает силу критического противостояния и служит синонимом права на свободное развитие личности; 2) посты, направленные на унижение и критику; 3) посты, содержашие совет, поддержку, утешение находящемуся 6 затруднительном положении «Я».

Ключевые слова: аутокоммуникация, коммуникативно-компенсаторные процессы, социальные сети, социология интернета.

\title{
КОМУНІКАТИВНО-КОМПЕНСАТОРНІ ПРОЦЕСИ В СОЦІАЛЬНИХ МЕРЕЖАХ
}

\author{
Тетяна Храбан, \\ кандидат філологічних наук, \\ дочент кафедри іноземних мов \\ Військового інституту телекомунікацій та інформатизації \\ Ігор Храбан, \\ доктор політичних наук, професор, \\ професор Міжрегіональної академї управління персоналом
}

\begin{abstract}
Мета статті - виявити специфіку комунікативно-компенсаторних процесів у соиіальних мережах.
\end{abstract}


Методи й методики. Для досягнення поставленої мети в роботі було використано загальнонаукові методи дослідження: аналіз, класифікацію, спостереження, опис. Крім того, у рамках комплексного соціолінгвістичного підходу були використані дискурс-аналіз $i$ квантитативний метод дослідження. Матеріалами дослідження були письмові публікації (nости), розміщені в українському секторі сочіальної мережі «Facebook».

Результати та дискусії. У дослідженні було виділено три модуси комунікативнокомпенсаторних процесів, які розташовані в порядку спадання їх питомої ваги: 1) комунікативно-компенсаторний процес, який характеризується кореляцією з механізмом психологічного захисту «надкомпенсація». При иъьому відбувається особистісне зростання й радикальні перетворення особистості в иілому на основі діалогічного взаємостверждення «Я» $i$ «Ти». На мовному рівні такий модус проявляється у використанні кристалізованого образу (реального або ілюзорного) для утвердження своєї сили, значущьості, иінності, тобто для самоствердження й підвищення статусу; 2) процес, який характеризується кореляцією з механізмом психологічного захисту «пряма компенсація», щзо носить адаптивний характер i не сприяє особистісному зростанню суб'єкта. На мовному рівні такий модус проявляється в зосередженні індивіда на своїх інтересах, почуттях $i$ потребах, орієнтаціі на споживання; 3) процес, який характеризується корелячією з механізмом психологічного захисту «ілюзорна надкомпенсачія», щуо носить характер психологічного вампіризму. На мовному рівні такий модус проявлясться у вишукуванні в іншої особистості уявних чи реальних недоліків, які акцентуються й гіпертрофовано перебільшуються.

Висновки. Специфічною особливістю комунікативно-компенсаторних прочесів у соиіальних мережах є те, щзо вони переважно виступають як репрезентації компенсаторної функиії аутокомунікації. Домінантною формою компенсаторної аутокомунікації 8 сочіальних мережах $\epsilon$ внутрішній монолог. Вербальною реалізацією комунікативнокомпенсаторних процесів у сочіальних мережах $\epsilon$ : 1) посади, у яких протест набуває чинності критичного протистояння й служить синонімом права на вільний розвиток особистості; 2) посади, спрямовані на приниження ци критику; 3) пости, які містять поради, підтримку, розраду тим, хто знаходиться в скрутному становищі «Я».

Ключові слова: аутокомунікація, комунікативно-компенсаторні процеси, сочіальні мережі, соціологія інтернету.

Submitted to the editorial office - 13.05. 2020

Reviewed-02.11.2020

Accepted for printing - 05.11.2020

Подано до редакиіiі-13.05.2020

Рецензовано - 02.11.2020

Прийнято до друку - 05.11.2020 